\title{
EFFECT OF TITANIUM-CONTAINING INOCULANTS ON STRUCTURE AND PROPERTIES OF WELD METAL OF HIGH-STRENGTH LOW-ALLOY STEELS
}

\author{
V.V. GOLOVKO, S.N. STEPANYUK and D.Yu. ERMOLENKO \\ E.O. Paton Electric Welding Institute, NASU \\ 11 Bozhenko Str., 03680, Kiev, Ukraine. E-mail: office@paton.kiev.ua
}

\begin{abstract}
There is a necessity in increase of toughness and ductility indices of weld metal of high-strength low-alloy steels. Effect of inoculants on process of solidification and formation of grains of primary structure is not studied enough. Possibility of regulation of grain size of primary weld metal structure by weld metal melt inoculation with refractory titanium compounds, included into flux-cored wire was considered. Distribution of non-metallic inclusions in weld metal on size and morphology was investigated. Examinations of primary and secondary weld metal structure were carried out. It is determined that entering of titanium refractory compounds into the weld pool allows changing the size of primary structure dendrites. It was found that presence of titanium compounds having poor wetting by liquid iron (TiN) at interface results in blocking of dendrite growth. At the same time, introduction of titanium compounds characterized by small liquid iron wetting angles ( $\mathrm{TiC}$ ), in the melt promotes for formation of coarser dendrites. It was shown that weld metal with bainite $(\mathrm{TiN})$ or ferrite $(\mathrm{TiC})$ secondary structures, which are close on strength indices but differ on ductility and toughness levels, can be obtained depending on inoculant structure. Obtained results are realized in technology for welding of HSLA steels using flux-cored wire with titanium-containing inoculants. Technology has passed experimental-industrial verification at Novo-Kramatorsk Machine-Building Works. 7 Ref., 5 Tables, 5 Figures.
\end{abstract}

Keywords: arc welding, low-alloy steels, fluxcored wire, introduction of titanium-containing inocu lants, weld metal, structure and properties

In recent decades, significant widening of volumes of application of high-strength low-alloy (HSLA) steels is one of the typical peculiarities of production of welded metal structures. Their application allows reducing metal intensity of the parts and decreasing energy consumption for their manufacture. Complex of mechanical properties of welded structure is determined by structure indices of base metal as well as metal of welded joint. If structure of cold-rolled metal is formed as a result of complex metallurgical and thermomechanical influence, then possibility of regulation of weld metal microstructure is highly limited. Non-metallic inclusions (NMI) are one of the effective means of such regulation.

Scientific and technical literature has large number of works investigating effect of inclusions on conditions of ferrite structure formation

Table 1. Melting temperature and angle of wetting by molten iron of titanium compounds at $1600{ }^{\circ} \mathrm{C}$ [6]

\begin{tabular}{||c|c|c|c||}
\hline \hline Inclusion & $T_{\text {melt }},{ }^{\circ} \mathrm{C}$ & $\theta$, deg & Lattice type \\
\hline $\mathrm{TiO}_{2}$ & 1750 & 78 & FCC, $a=0.417 \mathrm{~nm}$ \\
\hline $\mathrm{TiN}$ & 2950 & 130 & FCC, $a=0.423 \mathrm{~nm}$ \\
\hline $\mathrm{TiC}$ & 3150 & 49 & FCC,$a=0.431 \mathrm{~nm}$ \\
\hline
\end{tabular}

(c) V.V. GOLOVKO, S.N. STEPANYUK and D.Yu. ERMOLENKO, 2015 and peculiarities of $\gamma \rightarrow \alpha$ transformations [1-3]. Significantly smaller amount of works is dedicated to investigation of role of NMI in processes of solidification and grain formation of the primary structure $[4,5]$. It is known fact that nature of re-solidification process can significantly differ depending on primary austenite grain size [4], and refractory inclusions, which are present in the metal melt, can influence dendrite growth conditions [5].

The aim of present research lied in investigation of possibility of regulation of grain size in primary structure of weld metal on HSLA steels, produced by $\left(\mathrm{Ar}+\mathrm{CO}_{2}\right)$-shielded flux-cored wire arc welding. It can be done by weld pool melt inoculation with refractory titanium compounds, included in wire core. Titanium compounds with different liquid iron wetting value at $1600{ }^{\circ} \mathrm{C}$ (Table 1) were taken as inoculants.

Table 2 gives chemical composition of weld metal, produced in accordance with the requirements [7].

Sections for investigation of peculiarities of NMI distribution and microstructure content as well as samples for determination of mechanical properties in accordance with the requirements of GOST 6996-66 were manufactured from weld metal. Results of determination of weld metal mechanical properties, given in Table 3 , showed that examined welds are close on strength indices $\left(\sigma_{t}, \sigma_{0.2}\right)$, but differ on ductility $\left(\delta_{5}, \psi\right)$ and toughness $(K C V)$ levels. 
Table 2. Chemical composition of examined welds

\begin{tabular}{||c|c|c|c|c|c|c|c||}
\hline \hline \multirow{2}{*}{ Inoculant } & \multicolumn{9}{|c|}{ Weight fraction in weld metal, \% } & Mo & $\mathrm{Ti}$ & $\mathrm{Al}$ \\
\cline { 2 - 9 } & $\mathrm{C}$ & $\mathrm{Mn}$ & $\mathrm{Si}$ & $\mathrm{Ni}$ & 0.26 & 0.013 & 0.038 \\
\hline $\mathrm{TiO}_{2}$ & 0.032 & 1.32 & 0.30 & 2.14 & 0.24 & 0.011 & 0.033 \\
\hline $\mathrm{TiC}$ & 0.046 & 1.39 & 0.34 & 2.10 & 0.26 & 0.011 & 0.036 \\
\hline $\mathrm{TiN}$ & 0.035 & 1.40 & 0.32 & 2.19 & 0 & 0 \\
\hline
\end{tabular}

Table 3. Mechanical properties of metal of examined welds

\begin{tabular}{|c|c|c|c|c|c|c|c|c|}
\hline \multirow{2}{*}{ Inoculant } & $\sigma_{\mathrm{t}}$ & $\sigma_{0.2}$ & $\delta_{5}$ & $\psi$ & \multicolumn{4}{|c|}{$K C V, \mathrm{~J} / \mathrm{cm}^{2}$, at $T,{ }^{\circ} \mathrm{C}$} \\
\hline & \multicolumn{2}{|c|}{$\mathrm{MPa}$} & \multicolumn{2}{|c|}{$\%$} & 20 & 0 & -20 & -40 \\
\hline $\mathrm{TiO}_{2}$ & 693 & 605 & 14 & 48 & 89 & 85 & 82 & 57 \\
\hline $\mathrm{TiC}$ & 715 & 644 & 19 & 63 & 95 & 89 & 85 & 73 \\
\hline $\mathrm{TiN}$ & 712 & 580 & 5 & 15 & 55 & 47 & 40 & 32 \\
\hline
\end{tabular}

Examination of peculiarities of NMI distribution was carried out on unetched sections using optical microscope «Neophot-30» and further computer processing of images for obtaining information on their volume content (Figure 1). Metallographic and fractographic examinations of weld metal samples were performed in sharing centers of the E.O. Paton Electric Welding Institute. Analysis of weld metal microstructure was carried out on transverse sections after etching in $4 \% \mathrm{HNO}_{3}$ solution in ethyl alcohol using scanning electron microscope JSM-35CF. Morphology and composition of NMI on fracture surfaces was examined with the help of Auger-microprobe JAMP 9500F, equipped by energy-dispersion X-ray spectrometer of INCA system (researcher L.M. Kapitanchuk).

Due to the fact that aim of the work lied in investigation of effect of introduction of refractory inoculants into the weld pool, the specific attention was paid to analysis of morphology and structure of NMI. It was determined that the inclusions in the studied samples can be divided on two main groups on morphological characteristics, namely single-phase and multi-phase. Single-phase inclusions of up to $0.3 \mu \mathrm{m}$ size in weld metal consisted of refractory particles of titanium oxides $\left(\mathrm{TiO}_{2}\right)$, titanium carbides ( $\mathrm{TiC})$ and titanium nitrides (TiN). Inclusions of this type of more than $0.1 \mu \mathrm{m}$ size were represented by silicate or manganese aluminum silicate compounds (Figure 2).

Analysis of morphological peculiarities of NMI of more than $0.5 \mu \mathrm{m}$ size showed that their center, as a rule, contain refractory inclusions with more fusible constituent precipitating on their surface during weld metal cooling. As can be seen from data given in Table 4, the metal of examined welds contained approximately equal fraction of inclusions of up to $0.3 \mu \mathrm{m}$, the main part of which are presented by refractory titanium compounds. However, this metal was different in grain size of primary structure as well as composition of secondary microstructure.
Figure 3 shows the samples of weld metal primary structure, obtained on «Neophot-30» after etching in boiling solution of sodium picrate. It also gives the results of measurement of thickness of dendrites, formed in process of metal soliditication.

As can be seen from data presented, inoculation of refractory titanium compounds in the weld pool effects the size of dendrite structure, forming during solidification. Nature of this effect, shown in Figure 4, allows making a conclusion that inclusions with increased energy of interaction with den-
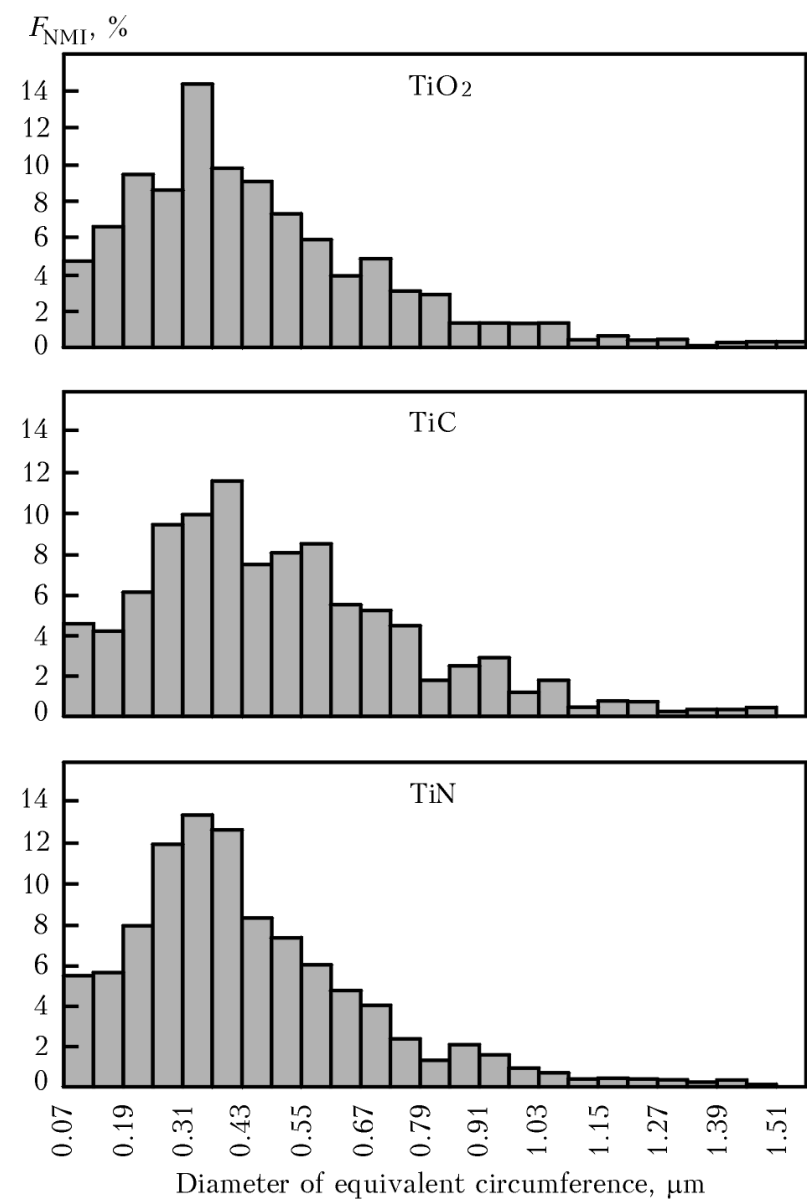

Figure 1. Distribution of NMI $F_{\mathrm{NMI}}$ in weld metal on their sizes 

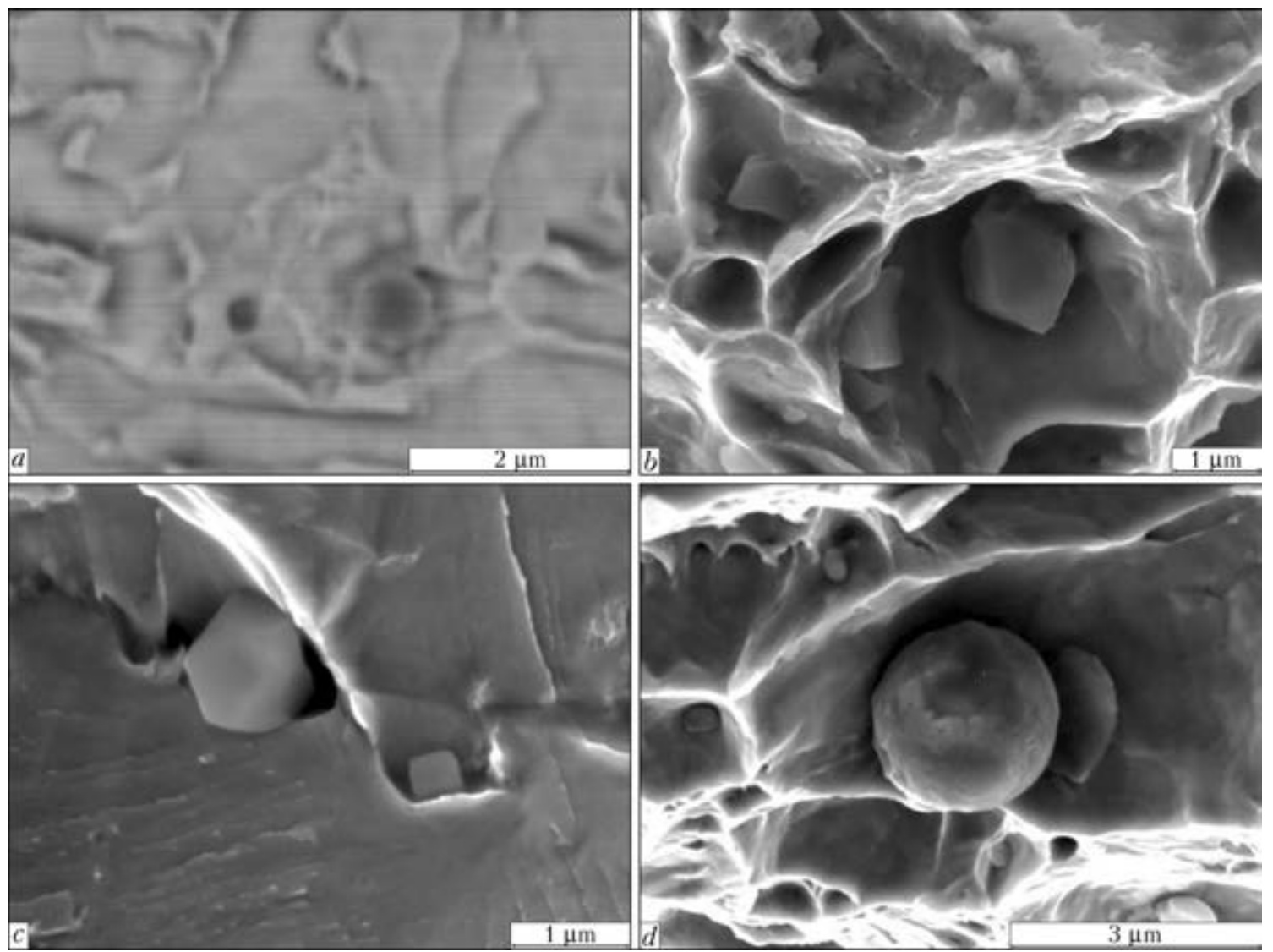

Figure 2. Morphology of NMI in weld metal: $a$ - aluminum oxide; $b-$ titanium carbide; $c$ - titanium nitride; $d-$ manganese aluminum silicate
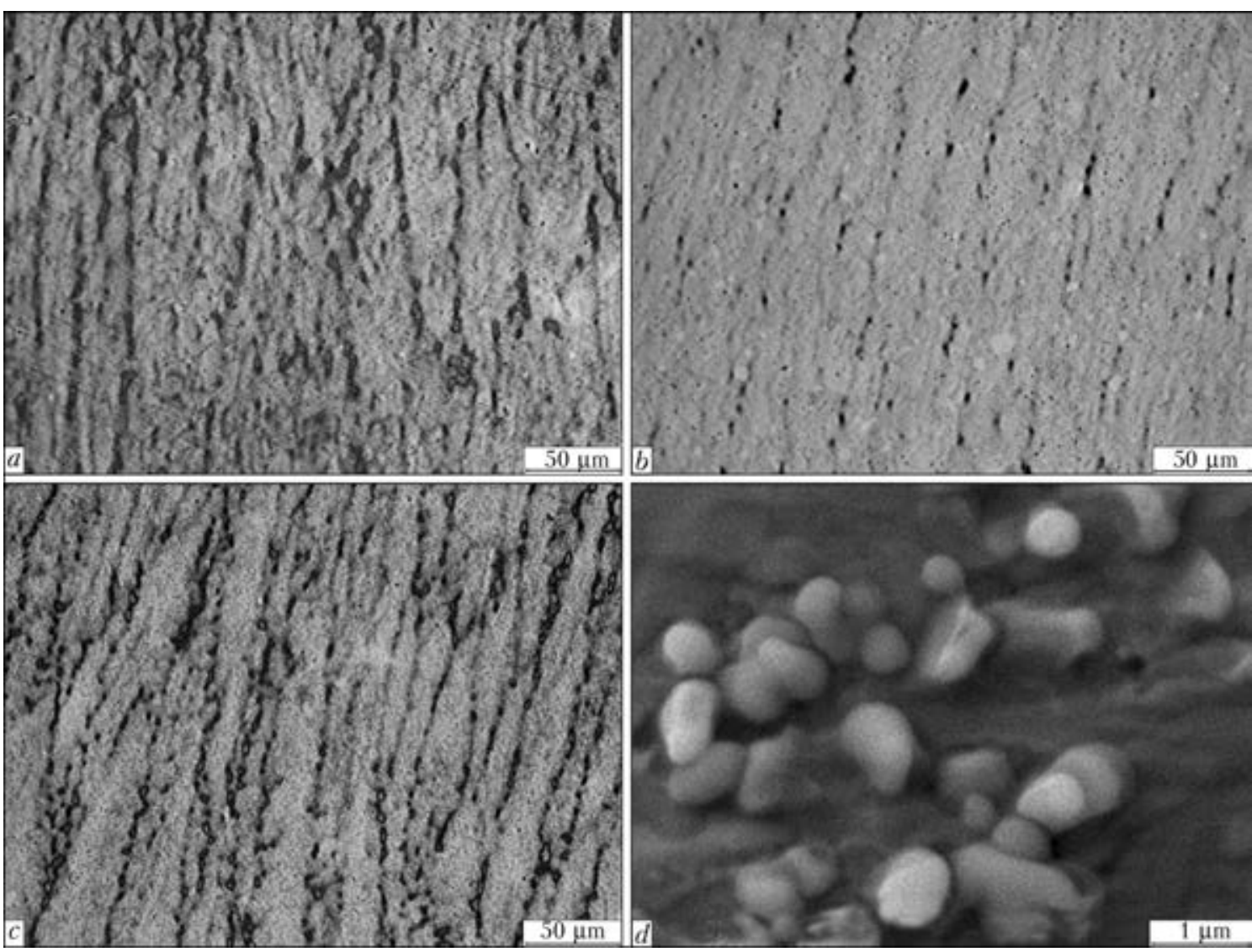

Figure 3. Primary structure of weld metal: $a-\mathrm{TiO}_{2} ; b-\mathrm{TiC} ; c-\mathrm{TiN} ; d-$ nanoparticles of refractory inclusions on interface 
Table 4. Fractional composition of NMI in examined weld metal

\begin{tabular}{||c|c|c|c||}
\hline \multirow{2}{*}{ Inoculant } & \multicolumn{3}{|c|}{ Volume fraction, \%, of inclusions of size, $\mu \mathrm{m}$} \\
\cline { 2 - 4 } & $<0.3$ & $0.3-0.8$ & $>0.8$ \\
\hline $\mathrm{TiO}_{2}$ & 29.64 & 61.54 & 8.82 \\
\hline $\mathrm{TiC}$ & 24.50 & 63.50 & 12 \\
\hline $\mathrm{TiN}$ & 31.11 & 60.59 & 8.30 \\
\hline
\end{tabular}

Table 5. Fraction of structural constituents in microstructure of weld metal, and results of determination of their hardness

\begin{tabular}{|c|l|c|c||}
\hline \multirow{2}{*}{ Inoculant } & Structural constituent & Hardness $H V$ & $\begin{array}{c}\text { Fraction in } \\
\text { microstructure, } \\
\%\end{array}$ \\
\hline \multirow{2}{*}{$\mathrm{TiO}_{2}$} & Acicular ferrite & $254-264$ & 60 \\
& Polyhedral ferrite & $236-254$ & 21 \\
& Polygonal ferrite & $250-254$ & 12 \\
& Lower bainite & $274-297$ & 8 \\
\hline \multirow{2}{*}{$\mathrm{TiC}$} & Acicular ferrite & $236-264$ & 56 \\
& Polyhedral ferrite & $213-216$ & 42 \\
& Polygonal ferrite & $224-228$ & 2 \\
\hline \multirow{2}{*}{$\mathrm{TiN}$} & Lower bainite & $300-309$ & 85 \\
& Polygonal ferrite + & $274-276$ & 9 \\
& bainite & $270-276$ & 6 \\
& Polyhedral ferrite + & & \\
& bainite & & \\
\hline
\end{tabular}

drite surface (Figure 3, $d$ ), present in solidification front, promote for rise of rate of its growth. This can be an explanation for significant increase of dendrite size in the case of titanium carbide inoculation in comparison with two other researched variants (Figure 4).

It is known fact that grain size of primary structure effects the nature of $\gamma \rightarrow \alpha$ transformation processes. Weld metal secondary structure was investigated using optical and electron metallography. It was determined that microstructure of welds consists of mixture of ferrite and bainite structures. Figure 5 shows the microstructure samples, and Table 5 gives the results of determination of fraction of separate structural constituents in it.

Analysis of microstructure composition of weld metal, obtained after completion of re-solidification processes, showed change of fraction of ferrite and bainite constituents in it depending on grain size of primary structure, that can be explained by competitive nature of two main processes of ferrite phase nucleation in course of $\gamma \rightarrow \alpha$ transformation. If dendrites of up to $100 \mu \mathrm{m}$ size are formed in the case of presence on solidification front of TiN inclusions, capable to suppress growth of solidifying $\gamma$-phase, then replacement of these inclusions to $\mathrm{TiC}$ particles promotes for increase of dendrite size to $150 \mu \mathrm{m}$.

In the fist case, boundaries of primary grains are the centers of $\alpha$-phase nucleation. This is the place for formation of bainite structure in high-

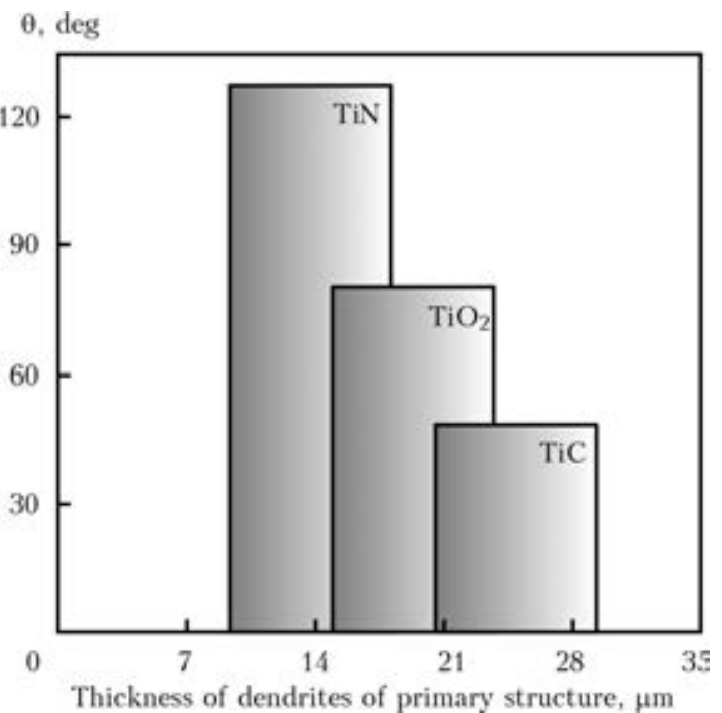

Figure 4. Relationship between angle of wetting of refractory compounds by liquid iron and thickness of dendrites of primary structure of investigated weld metal

temperature area of intermediate transformation. In the second case, with coarser austenite grains, nucleation of new phase on interface surface of some NMI with metallic matrix becomes more energy profitable. In this situation, process of bainite transformation is shifted in the area of lower temperatures, that promotes for formation of ferrite structures of acicular morphology. Such a conclusion about effect of titanium-containing inoculants on conditions of formation of weld metal microstructure in HSLA steels is verified by results of experiments carried in given work.

Complete understanding of effect of inoculants introduced into the weld pool on formation of weld metal primary structure requires detailed investigation of physical-chemical peculiarities of these processes. Results of such investigations will be stated in the next publications dedicated to this subject.

\section{Conclusions}

Effect of titanium-containing inoculants on conditions of structure formation in weld metal of high-strength low-alloy steels was investigated. It is determined that size of primary structure dendrites can be changed by introduction of refractory titanium compounds into the weld pool. Presence of titanium nitrides on interface results in blockage of dendrite growth, whereas introduction of titanium carbides into the melt promotes for formation of coarser dendrites. Change of primary structure size influences the nature of $\gamma \rightarrow \alpha$ transformation processes. If nucleation of $\alpha$-phase in disperse dendrite structure is started at grain boundaries in upper area of bainite transformation, then nucleation of ferrite inside the 
SCIENTIFIC AND TECHNICAL
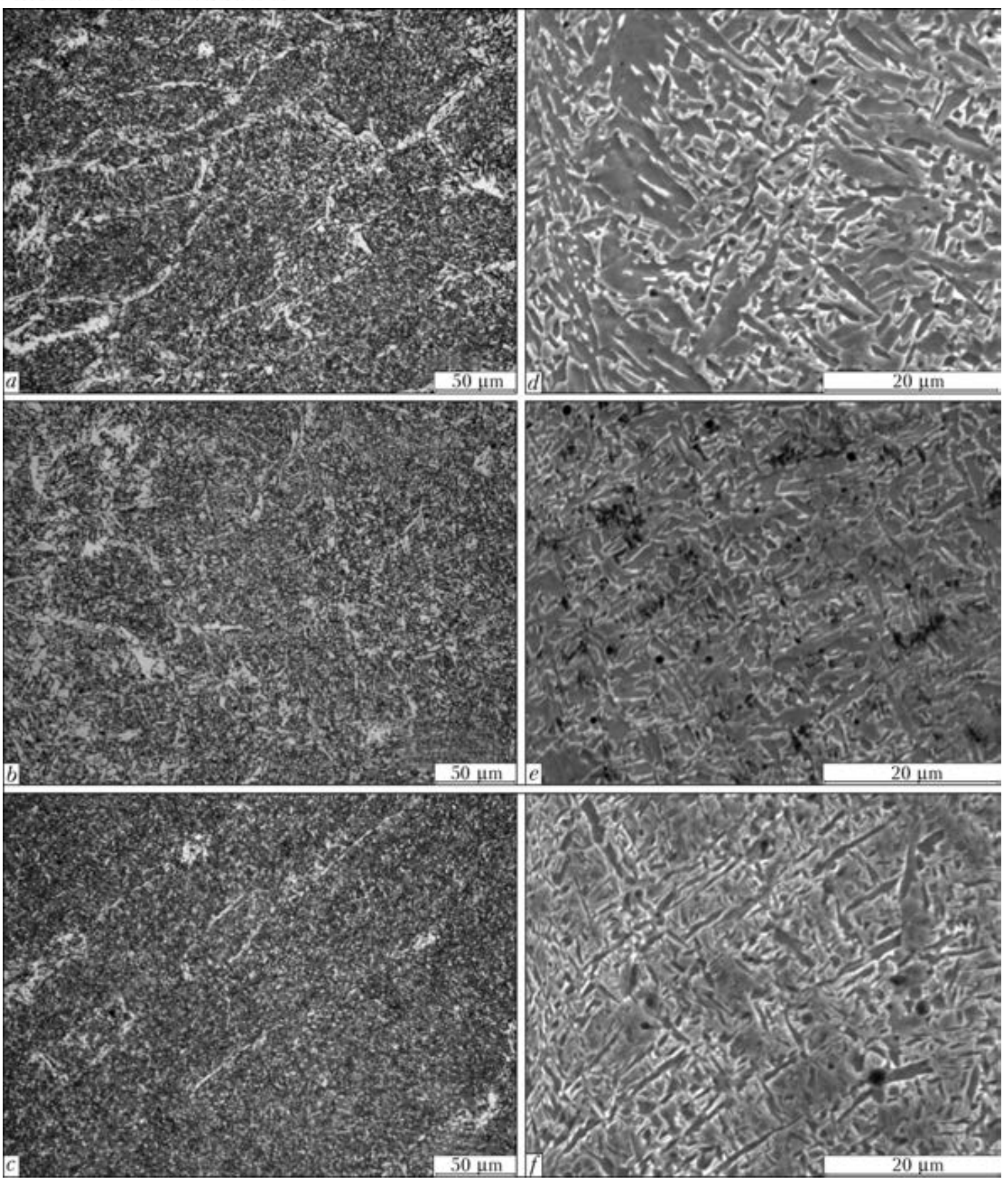

Figure 5. Microstructure of examined weld metal: $a, d-\mathrm{TiO}_{2} ; b, e-\mathrm{TiC} ; c, f-\mathrm{TiN}$

primary grains at boundaries with non-metallic inclusions at temperatures close to ending of bainite transformation is typical for coarser dendrites. It is shown that weld metal with bainite (TiN) or ferrite (TiC) secondary structures, which are close on strength indices but differ on the level of ductility and toughness, can be obtained depending on inoculant composition.

1. Lee, T.-K., Kim, H.J., Kang, B.Y. et al. (2000) Effect of inclusion size on the nucleation of acicular ferrite in welds. ISIJ Int., 40(12), 1260-1268.

2. Oh, Y.J. Lee, S.-Y., Byun, J-S. (2000) Non-metallic inclusions and acicular ferrite in low carbon steel. Materials Transact., 41(12), 1663-1669.
3. Babu, S.S. (2004) The mechanism of acicular ferrite formation in weld deposits. Current Opinion in Solid State and Materials Sci., 8, 267-278.

4. Zhang, L., Thomas, B. (2006) State of the art in the control of inclusions during steel ingot casting. Metallurg. and Materials Transact., 37(5), 733-761.

5. Vanovsek, W., Bernhard, C., Fiedler, M. et al. Influence of alloying additions on the morphology of non-metallic inclusions in high-strength steel welds. IIW Doc. II-1776-11 (II-C-421-11).

6. Lyakishev, N.P., Pliner, Yu.L., Lappo, S.I. (1985) Alloys and steels doped with titanium. Moscow: Metallurgiya.

7. ISO 26304:2011: Welding consumables. - Solid wire electrodes, tubular cored electrodes and electrode-flux combinations for submerged arc welding of high strength steels. - Classification. 